\title{
La colaboración entre los expertos $y$ el movimiento sindical frente a los desafíos locales de la globalización.
}

\author{
Daniel Oscar Dicósimo*
}

IGEHCS - CONICET, ARGENTINA

\section{ResUMEN}

Este artículo es un estudio histórico de la colaboración entre los movimientos sindicales de la Argentina y el Brasil y los expertos en relaciones laborales de estos países, ante la reestructuración productiva y la flexibilización laboral, implementadas entre 1990 y 2002. La nueva institucionalidad micro - regulatoria, en otras palabras los nuevos parámetros, las nuevas reglas, los nuevos espacios y objetivos que incorporaron las empresas automotrices y metalmecánicas a la producción, pronto se presentaría como un desafío para los dirigentes en las negociaciones colectivas e impulsó a los técnicos al primer plano de las negociaciones colectivas entre sindicatos y empresas.

\begin{abstract}
This article is a historic research of the collaboration between syndical movement and experts in labor relations in Argentina and Brazil. It takes place in 1990-2002 when a productive restructuring and labor flexibility was implemented. The new micro institutions - regulation, integrated by the new parameters, new rules, new spaces and objectives that incorporated the automotive and metalworking production companies was soon presented as a challenge for leaders in the collective negotiations, prompting technicians to the forefront of collective negotiations between unions and businesses.
\end{abstract}

*daniel.dicosimo@speedy.com.ar 


\section{INTRODUCCIÓN}

ste artículo es un estudio histórico de las respuestas de los movimientos sindicales de la Argentina y el Brasil ante la reestructuración productiva y la flexibilización laboral, implementadas en esos países entre 1990 y 2002, y en particular un acercamiento al tema de la colaboración entre dichos movimientos y los expertos en las relaciones laborales de ambos países.

Antes que nada es necesario definir a nuestro sujeto de análisis específico: ¿qué entendemos por “experto”?. El término proviene de la segunda posguerra y tuvo una fuerte influencia de las ciencias sociales norteamericanas, en palabras de Federico Neiburg y Mariano Plotkin: "Los expertos modernos suelen ser los técnicos, los especialistas que trabajan en y para el Estado, y más recientemente para las ONG, y los organismos internacionales." (Neiburg y Plotkin, 2004: 15) En buena medida los expertos han construido su identidad profesional en contraste con la del intelectual:

"Si la figura del intelectual remite a un tipo de formación general, que puede o no tener a la universidad como ámbito principal de acción, la figura del experto evoca especialización y entrenamiento académico. En su acción pública, el primero dice anteponer un conjunto de valores y un tipo de sensibilidad; el segundo, al contrario, actúa en nombre de la técnica y la ciencia, reclamando hacer de la neutralidad axiológica la base para la búsqueda del bien común." (Neiburg y Plotkin, ídem.)

Sería un error tratar de comprender a estos actores adoptando, como punto de partida, sus propias categorías de identificación basadas en tal dicotomía. Aquí adoptaremos la alternativa propuesta por Neiburg y Plotkin, es decir que en lugar de caracterizar a los expertos solo a partir de su especialización académica y su neutralidad axiológica, tendremos en cuenta también que hay en la realidad social pasajes de un espacio a otro, por ejemplo entre el Estado, la academia o las organizaciones sociales, e incluso puntos de intersección productiva con los intelectuales, que enriquecen y orientan sus concepciones de lo social, lo que dichos autores 
consideran como "los pasajes y la circulación de individuos, ideas, modelos institucionales y formas de intervención" (Neiburg, Plotkin: 17)

Por otra parte, la perspectiva de este estudio es propia de la historia comparada, aunque admite y requiere ser combinada con las historias conectada y transnacional. La opción por la historia comparada se justifica, en primer lugar, por una cuestión metodológica: Argentina y Brasil son dos sociedades cercanas en el espacio y que atravesaron en forma sincronizada procesos históricos análogos. Constatar semejanzas y diferencias en esos procesos, establecer nuevas preguntas y buscar los problemas comunes a ellas, es un procedimiento muy eficaz para ampliar el horizonte del historiador más allá del "provincianismo" de las historias nacionales o locales. En segundo lugar, la ampliación de la perspectiva puede facilitar una mirada crítica sobre cuestiones "naturalizadas" por las historias nacionales, y en este sentido repensar los problemas complejos de nuestra sociedad. Todo esto dentro del rigor del método histórico que seamos capaces de alcanzar, evitando las yuxtaposiciones y las clasificaciones en el análisis de los procesos históricos seleccionados.

La historia comparada ha sido criticada por quienes levantaron las perspectivas más recientes de la historia conectada y la historia transnacional. Serge Gruzinski señala que la historia comparada, si bien fue pensada como una alternativa a la estrechez de las historias nacionales, ha recaído en el euro centrismo debido a su método, la elección de los objetos a comparar, etc. Como alternativa propone que el historiador trabaje con las conexiones entre grupos y sociedades, ya que las historias conectadas son para él múltiples y ligadas entre sí; y en esta perspectiva da valor a los passeurs, actores que, en mundos globalizados, han sido mediadores entre los diversos grupos y sociedades, contribuyendo a establecer conexiones entre ellos. (Cohelo, 2011: 15) Asimismo, desde la historia transnacional se ha señalado que la historia comparada no puede apreciar el valor del enfoque relacional, es decir no visualiza las relaciones de poder y dominación entre los grupos sociales.

Como señalamos antes, nuestro tema de estudio y las fuentes 
ligadas al mismo admiten y requieren combinar los enfoques de las historias comparada, conectada y transnacional. La sincronización y las analogías con que se presentaron los fenómenos de reestructuración productiva y flexibilización laboral en Argentina y Brasil nos habilitan a buscar los problemas comunes entre estas sociedades, pero asimismo requieren que consideremos que la conexión y el intercambio de ideas y personas entre una y otra pueden ser una clave interpretativa para comprender las reacciones sindicales a los desafíos de la globalización. No se trata de establecer cuál de los dos movimientos sindicales respondió más apropiadamente a los mismos, en virtud de trayectorias y de tradiciones que los diferencian históricamente, porque caeríamos así en el error de la jerarquización de comportamientos según patrones modales, sino de partir del supuesto que los actores sindicales estuvieron conectados e intercambiaron información y diagnósticos de situación, a partir de sus experiencias y repertorios locales, que les habrían permitido construir estrategias tanto globales como nacionales, y que los expertos tuvieron un papel significativo en esta coalición.

\section{FleXibilización LABORAL Y REACCIÓN SINDICAL}

En la década de 1990 Argentina y Brasil abandonaron el modelo de economía cerrada y de crecimiento basado en la industrialización sustitutiva de importaciones, y adoptaron otro de apertura comercial y financiera, privatizaciones y flexibilización laboral. Los cambios eran motivados por factores semejantes: magros rendimientos económicos, alta inflación, pérdida de confianza en las monedas nacionales, gravosa carga de la deuda externa y progresivo dominio de las ideas neoliberales. El marco político de estas reformas, sin embargo, fue diferente entre ambos países: un proceso estable y prolongado en Argentina, con los dos gobiernos de Carlos Menem (1989 a 1999), y uno signado por el juicio político a Color de Mello, que había asumido en 1989, el interinato de Itamar Franco y los dos mandatos de Fernando Enrique Cardoso (1995 a 2002) en el Brasil.

En los dos casos la estabilización fue de la mano con el ajuste estructural, que desmontó los mecanismos económicos y fiscales 
existentes desde la década de 1930, pero hay diferencias en el momento del proceso en que se aplicaron tanto uno como otro. En Argentina Menem adoptó, luego de algunas vacilaciones, una tasa fija de cambio que establecía una paridad dólar - peso de uno a uno y consiguió restaurar la confianza en la moneda, controlando la inflación y el déficit fiscal. Solo en una segunda etapa comenzaron las privatizaciones de empresas propiedad del Estado y la desregulación laboral y del sistema de salud. La apertura comercial y las privatizaciones son decididas al comienzo del proceso por Collor de Mello, y seguidas por el Plan Real, concebido durante el gobierno de Itamar pero bajo supervisión de Cardoso, que incluía un régimen de cambio administrado - una especie de ancla cambiaria - luego sustituido por otro de cambio fluctuante y metas de superávit primario e inflacionarias. El éxito del plan, que conseguiría estabilizar la inflación y establecer una nueva moneda, permitió la reelección del presidente y profundizar la flexibilización laboral (Devoto y Fausto, 2008: 452)

En los dos países la apertura económica se caracterizó por un gran desorden y apresuramiento, provocando el ingreso precipitado de las economías al mercado global. Además de alentar el discurso de la competitividad, que ya venía creciendo en la década anterior, la apertura forzó a las empresas locales a expandir los procesos de reestructuración productiva, que incluyeron cierre de fábricas, renovación tecnológica, tercerización, subcontratación, reorganización de los procesos productivos, entre otros, y que apuntaba a racionalizar los costos del factor trabajo (da Silva Costa, 2003: 7) En Argentina ya en la década de 1980 se acordaban informalmente algunas cuestiones, como la contratación por tiempo determinado y los cambios en la duración de la jornada, la organización del trabajo y la modalidad de las remuneraciones, que recién en el segundo gobierno de Menem tendrán un soporte legal.

\section{LA FLEXIBILIZACIÓN LABORAL.}

La política laboral de los gobiernos argentino y brasilero, con su eje en la flexibilización, tuvo el propósito de ser funcional a la estabilización 
económica, neutralizar el poder sindical en las empresas, facilitar la reasignación de la mano de obra y disminuir los costos empresariales, constituyendo de esa forma un nuevo marco institucional que restaurara la confianza empresarial en el modelo económico y fuera atractivo para la radicación de inversiones extranjeras (Battistini, 2000: 6; Devoto y Fausto: 452) La definición de flexibilización que adoptamos en este artículo se ajusta a las realidades de esta coyuntura histórica y espacios nacionales, teniendo en cuenta lo "genérico y proteiforme" del término que ha señalado Battistini (ídem, 48). El concepto aplicable a estos dos casos debe considerar tres dimensiones: a) flexibilización en un sentido estricto, asociada al derecho individual del trabajo; b) reformas asociadas al derecho colectivo del trabajo y c) reducción directa de impuestos patronales a las obras sociales y desregulación del sector salud (Etchemendy y Palermo, 1998: 562; Battistini: 6)

También es interesante considerar el proceso de cambio de la legislación laboral como una batalla política, por cuanto la reforma de instituciones como las leyes del trabajo implicaba cambios en la distribución del poder y las relaciones de fuerza de los actores sociopolíticos (Etchemendy y Palermo: 563) En este sentido, los sindicatos adoptaron una posición defensiva ante los cambios, como veremos más abajo, ante la perspectiva de que pudieran afectar su representación histórica y legal. En otras palabras, un conjunto de derechos corporativos entre los cuales destacan la personería gremial, que los habilitaba para representar a todos los trabajadores de un sector de actividad en la negociación colectiva, y la administración de las obras sociales sindicales.

En la Argentina el puntapié inicial de la reforma fue la Ley de Empleo, enviada por el gobierno al Congreso en 1989, que preveía una serie de nuevas modalidades de contratación con plazos determinados y con menores cargas sociales. Más allá de algunas modificaciones al proyecto original, significó un cambio en la rigidez garantista tradicional de la Ley de Contrato de Trabajo, pero no tendría un impacto mayor en el mercado laboral ni la simpatía de las cámaras empresarias. No obstante, entre 1990 y 1993 casi todos 
los intentos reformadores provenientes del gobierno fueron frenados en el Parlamento, a excepción de una reforma a la Ley de Accidentes de Trabajo (Ley 24.028)

Recién a partir de 1994, cuando el Ministerio de Trabajo adopta una política de "modernización concertada" la reforma volvió a tomar impulso, esta vez en dirección a "modificar los equilibrios entre derechos y deberes del trabajador y de revisar los mínimos legales inderogables con el objetivo de transformar la negociación colectiva en el ámbito primordial donde se discutan los niveles de garantismo" (Etchemendy y Palermo: 569) La política desreguladora tendría ahora el consenso de todas las partes involucradas, inclusive la CGT, y ello se plasmó en el llamado "Acuerdo Marco para el empleo, la productividad y la equidad social" (1994) Y, como efecto de ello, en el último ańo y medio del primer gobierno de Menem se sancionará el grueso de la reforma: flexibilización en las modalidades de contratación, reforma integral del régimen de Accidentes de Trabajo, nueva ley de quiebras, ley de mediación para disminuir la litigiosidad laboral, entre otras. No obstante, en el segundo gobierno y después de su exitosa reelección de 1995, Menem dará nuevo impulso a la desregulación, eliminando la ultra actividad de los convenios colectivos de trabajo y promoviendo la negociación colectiva en las empresas, como vemos más abajo.

De forma semejante, en Brasil el proceso reforma laboral no pudo desarrollarse de modo lineal ni alcanzar todos los objetivos que el gobierno y los empresarios se habían propuesto. Una parte sustancial de los cambios implicó la desregulación del sistema legal o Consolidación de las Leyes del Trabajo (CLT), que había sobrevivido desde su creación en el Estado Novo de la década de 1930. Entre otras medidas se instituyó el contrato por tiempo determinado o "banco de horas", que permitía adecuar la jornada de trabajo a períodos de aumento o baja de la producción, el trabajo en tiempo parcial, la suspensión temporaria del contrato laboral por motivos económicos, etc. No obstante uno de los cambios importantes que se esperaban, como imponer la preponderancia de los contratos colectivos de trabajo sobre las normas de la CLT, fue bloqueado en 
el Congreso federal (da Silva Costa: 3; Devoto y Fausto: 468)

Una dimensión de la reforma que confluía con la anterior fue la de los procedimientos en la Justicia del trabajo. Con la excusa de superar su arcaísmo y lentitud se hicieron una serie de cambios: la introducción del proceso sumarísimo para juicios de valor reducido, la extinción de la figura de los jueces clasistas y la creación de las comisiones de conciliación previa en las empresas. Es controvertido el papel que asumiría la Justicia del Trabajo en el nuevo modelo laboral: para algunos autores las partes representadas en las relaciones laborales privilegiaron la vía judicial para resolver conflictos y dejaron al margen la negociación, para otros la justicia dejó de ser predominante en los procesos de negociación colectiva, sobre todo por la estabilidad de la moneda y la caída de la inflación. No obstante, señala da Silva Costa, siguió vigente en las cuestiones de derecho que acompañaron los procesos de reestructuración empresarial, en cuestiones como renuncias de trabajadores (en sectores tradicionales como el textil las renuncias no eran compensadas con indemnización), flexibilización ocupacional (que demostró ser problemática en la administración de las horas trabajadas) o de la jornada laboral.

\section{LA REACCIÓN SINDICAL.}

La desregulación laboral, combinada con el control de la inflación y el elevado desempleo, provocó cambios forzados e imprevistos en los movimientos sindicales de ambos países. En la Argentina, el sindicalismo peronista mayoritario vio desdibujarse rápidamente el papel de representante político de quienes sufrían las consecuencias de la crisis de la deuda externa, que había desempeñado durante los años ochenta, y se dividió en varias agrupaciones, perdiendo el peso y la iniciativa política que había disfrutado dentro del movimiento peronista. Para peor debió soportar las críticas que le dirigía una nueva corriente sindical integrada por dirigentes y activistas peronistas, de las izquierdas e independientes, la Central de Trabajadores Argentinos (CTA), que tuvo su antecedente directo en el Congreso de los Trabajadores Argentinos creado en 1992. Mientras que 
en Brasil, la Central Única de Trabajadores (CUT), heredera del ímpetu clasista y anticapitalista del "nuevo sindicalismo" surgido de las grandes huelgas del ABC paulista, entre 1978 y 1980, veía con impotencia que la acumulación de fuerzas de la década de 1980 no serviría para frenar y mucho menos revertir la apertura económica y la flexibilización laboral, por cuanto el crecimiento del desempleo, la precarización laboral y el control de la inflación debilitaban las herramientas de acción colectiva y solidaria tradicionales.

La adhesión inicial de los dirigentes sindicales peronistas al gobierno era consecuente con su identidad política, pero cuando éste emprendió las reformas laborales se enfrentaron al dilema de quedarse en el lado oficialista y perder protagonismo político, o pasar a la oposición y arriesgar los privilegios corporativos de sus organizaciones (Palomino, 2005) El sindicalismo peronista perdía rápidamente su capacidad de articulación social, en la medida que los efectos de la política económica incrementaban el desempleo y el empleo informal, pero aunque quisiera ya no podía bloquear ni cambiar las variables macroeconómicas. Su tradicional influencia en el movimiento peronista, del cual había sido "columna vertebral" hasta 1983, fue erosionada por la opción tomada por la "rama política" a favor de un clientelismo de base territorial, que fortalecía a los aparatos partidarios a nivel provincial y municipal (Levitsk, 2004)

Por otra parte, la posición defensiva que adoptaron los dirigentes oficialistas puede atribuirse al impacto disgregador de las reformas laborales, que fragmentaron sus orientaciones estratégicas y volvieron obsoletas sus prácticas gremiales. La posición ante los cambios de los sindicatos que éstos presidían ya no era unánime; la puja salarial tradicional, basada en los reajustes a través de la negociación colectiva, no podía aplicarse; el esquema de negociación colectiva cambió, volviéndose cada vez más descentralizado. Asimismo, la debilidad política resultó en la pérdida de posiciones en el gobierno, como el Ministerio de Trabajo, un privilegio corporativo celosamente defendido hasta entonces; el apoyo brindado a Menem no se tradujo en influencia sobre el diseño de las políticas laborales, en parte por la 
falta de proyectos y en parte por la tendencia del presidente a consultar a los grupos económicos. Y los efectos negativos de la desregulación profundizaron la distancia entre representación y representatividad, marcaron una brecha de intereses entre dirigentes y bases obreras y, paradójicamente, dieron a los primeros más autonomía para decidir si apoyaban o criticaban las políticas gubernamentales (Palomino, 2005; Senén González, 1999)

En el Brasil muy pronto se hizo evidente que la fuerza política y social acumulada durante la década anterior no resultaría suficiente para enfrentar con éxito las iniciativas aperturistas de Collor. Las dos grandes centrales sindicales, la CUT y la CGT de Magri, organizaron en conjunto una huelga general para presionar por mejores salarios; ante la que el gobierno reaccionó modificando la ley de huelga en el sentido de sancionar a quienes paralizaran los servicios esenciales (Santana, 2011:4) La capacidad de movilización sindical fue debilitándose por la continuidad, en el gobierno de Fernando Enrique Cardoso, de medidas de control sobre las huelgas en el sector público. La represión de la huelga de petroleros fue un punto de inflexión a partir del cual esa capacidad disminuiría notoriamente.

A nivel estructural, el éxito del Plan Real en la estabilización de la moneda y el proceso de flexibilización de las relaciones laborales supusieron duros golpes al sindicalismo brasilero, por cuanto restaron poder de convocatoria a las reivindicaciones salariales y redujeron dramáticamente el sector de empleo formal. Durante las dos presidencias de Fernando Enrique Cardoso el índice de desempleo pasó de 4,8\% de la PEA en 1995, al 7,2\% en el segundo semestre de 2002, debido a un crecimiento modesto de la economía y a la modernización tecnológica y organizativa de las empresas. A la destrucción de puestos de trabajo, se calcula que entre 1989 y 1999 desaparecieron más de un millón y medio, hay que agregarle el crecimiento notorio del trabajo informal y el desplazamiento de muchos trabajadores al sector de servicios y de comercio, donde predominaban contratos de baja calificación y bajísimos salarios (Devoto y Fausto: 465; da Silva Costa: 7) 
Y en ese contexto, como causa y a la vez consecuencia, avanzaron los procesos de desregulación laboral. Las reformas de la CLT significaban un retroceso en el espacio conquistado por los sindicatos durante los ańos ochenta: fueron un traspié para el debate sobre la reducción de la jornada laboral como medio para aumentar el empleo y descolocaron las iniciativas de democratización del sistema corporativo, debiendo optar aquéllos por priorizar la desregulación de los derechos sociales y las relaciones laborales (de Silva Costa: 8) La modernización de la producción y las relaciones de trabajo amenazaron directamente al polo organizado y formalizado de la clase trabajadora, lo formal se convirtió en informal y, sumado al aumento del desempleo, afectó la tasa de sindicalización y disminuyó la capacidad de movilización sindical (Santana, 2000, 187)

\section{A. "Separación estructural y aproXimación coyUntural"} La opción tomada por el gobierno de Menem a favor de un modelo económico neoliberal y de una reforma laboral consecuente con éste provocó la división del frente sindical. Mientras un sector de la Confederación General del Trabajo (CGT) se mantuvo junto al gobierno, apoyando sus políticas, los sindicatos agrupados en el Movimiento de Trabajadores Argentinos (MTA) tomaron una distancia crítica de ambos; al mismo tiempo surgía la CTA como central obrera alternativa en 1996.

El MTA, constituido en 1994, tenía una composición mayoritaria de sindicatos del transporte, como colectiveros y camioneros, y su visión "permaneció anclada en su orientación hacia el Estado, típica del sindicalismo peronista, pero a diferencia de éste no subordinó su acción a la del PJ, ya que en su seno existen tanto dirigentes que adhieren a diferentes partidos, como otros que sostienen posiciones autónomas. Predominaba en sus dirigentes la expectativa de reformulación del rol del Estado intervencionista en la economía, capaz de mediar en las relaciones entre capital y trabajo y orientador de políticas redistributivas de ingreso favorables a los asalariados. Los límites de esa visión residen posiblemente en la dificultad de reiterar estrategias tradicionales ante los cambios registrados por la 
estructura ocupacional y social, lo que acotaba su base de acción.” (Palomino: 408)

La CTA, en cambio, surgió con planteos estratégicos novedosos desde el mismo momento de su fundación, ya que se posicionó como una central autónoma, independiente tanto del Estado, los partidos políticos y las empresas (Palomino: 410) Dejó de lado el esquema de afiliación tradicional de la CGT, por organizaciones, adoptando la afiliación individual y el voto directo de los afiliados, en lugar del indirecto por delegados, para la elección de sus autoridades. Asimismo aceptó en su seno organizaciones no sólo sindicales, como agrupamientos de jubilados y de desocupados, en lo que fue pionera, organizaciones de derechos humanos y ONG. Si bien su núcleo estaba compuesto de sindicatos estatales, como ATE y CTERA, y algunos sindicatos industriales disidentes como la UOM Villa Constitución, sus dirigentes se abrieron a convocar acciones “movimientistas" destinadas a reivindicar y promover derechos más amplios que los específicamente sectoriales del sindicalismo.

También el movimiento sindical brasilero estaba dividido en varias centrales durante la década de 1990, y también sus diagnósticos y tácticas sobre la apertura económica, la desregulación laboral y sus consecuencias fueron diferentes. La CUT era la organización más importante, había sido creada en 1983 durante el Segundo Congreso Nacional de la Clase Trabajadora, también llamado CONCLAT. Representaba el "nuevo sindicalismo" y en su nacimiento había levantado objetivos radicales, como una reforma agraria radical bajo control de los trabajadores y ocupación y expropiación de latifundios, no pago de la deuda externa, rechazo a las privatizaciones, elecciones directas de presidente, etc. La Confederación General del Trabajo (CGT) de Magri, así llamada por su secretario general Antônio Rogério Magri, se había constituido en 1986 y representaba el "sindicalismo de resultados", pragmático, que prefería las presiones y los acuerdos aislados con las empresas en lugar de las movilizaciones y huelgas nacionales. Esta corriente se pronunció tempranamente a favor de la economía de mercado, levantándose como oposición al "sindicalismo contestatario" y al socialismo de la CUT. La tercera 
central, Fuerza Sindical (FS), nació en 1991 y se presentó como una alternativa a la CUT y a la CGT de Magri, como una tercera vía entre el "radicalismo y partidismo inconsecuente" y una "propuesta conservadora" (Martins Rodrigues, 1992: 36)

A la defensiva y dividida, la corriente mayoritaria del sindicalismo, que conducía la CGT y apoyaba a Menem, optó por adaptarse a las nuevas reglas del juego. Por un lado, el intercambio y la negociación política con el gobierno permitirían defender las prerrogativas corporativas de los sindicatos, en particular la representación legal y el control de los fondos de las Obras Sociales (Palomino: 406) Por otro lado, al aceptar las presiones del gobierno en el sentido de negociar nuevas convenciones colectivas y la incorporación a las mismas de nuevas pautas de reorganización del trabajo, los sindicatos advirtieron que se allanaría el camino tanto para un aumento salarial como para renovar su legitimidad ante sus bases obreras (Battistini: 255)

La estrategia de intercambio y negociación tuvo un espacio y una herramienta privilegiada en la Comisión de Legislación del Trabajo de la Cámara de Diputados, que el sindicalismo peronista controlará hasta el año 1995; esa posición institucional le permitió bloquear las iniciativas gubernamentales en las que no había tenido participación e intervenir en la negociación de los proyectos que pasaban por el Parlamento (Etchemendy y Palermo: 577) Por ejemplo, la Ley de Empleo (1991) fue aprobada después de una negociación con la CGT San Martín, en la cual el Estado ofreció hacerse cargo de las deudas de sindicatos y obras sociales. Asimismo, esa línea política del sindicalismo se expresará en la participación en el ya citado "Acuerdo Marco para el empleo, la productividad y la equidad social”, al cual la nueva conducción oficialista de la CGT aportaría sus técnicos para la redacción de los proyectos de ley.

Los frutos de la respuesta "conservadora adaptativa" parecían elocuentes, ya que había anulado la iniciativa gubernamental de reforma vía parlamentaria, excluía de la misma la separación de las conducciones nacionales de los sindicatos de la negociación colectiva en las empresas y la ultra actividad, frenaban la desregulación del 
sector salud, una iniciativa planteada por el gobierno en 1991 pero congelada dos años después por necesidades políticas, y las organizaciones recibían compensaciones monetarias para sus obras sociales (Etchemendy y Palermo: 570-578)

Un aspecto importante de la nueva estrategia del sector cercano al gobierno será la conformación de un "sindicalismo de negocios", que aprovechaba el campo empresarial generado por las privatizaciones y las desregulaciones en materia de Obras Sociales. Esta última disponía que la afiliación del trabajador a las Obras Sociales sería libre a partir de 1997 y las obras deberían competir entre sí (las empresas de medicina privadas quedaron al margen de la competencia), para redefinir a la masa de afiliados sindicales "como una población "cautiva” (a través del vínculo de representación) para la venta de servicios" (Palomino: 404; Etchemendy y Palermo: 579)

La autonomía y la diferencia de intereses entre dirigentes y trabajadores, generadas por la brecha entre representación y representatividad, será un factor clave para el desarrollo de empresas sindicales. Aquí partimos del supuesto de que la relación entre representación y representatividad es problemática, se trata de dos cuestiones complementarias que, sin embargo, no siempre aparecen juntas (Drolas, 2004: 370 - 374). La representación podría definirse como la atribución de ocuparse de las cuestiones propias de la condición obrera, dada por la tradición y un marco legal, y la representatividad como "...la capacidad de homogeneizar lo heterogéneo”, respectivamente. Porque la distancia creciente entre dirigentes y afiliados dieron a los primeros, paradójicamente, más autonomía para decidir si apoyaban o criticaban las políticas gubernamentales y para optar por una orientación hacia el "sindicalismo de negocios".

Si bien las tres centrales brasileras coincidieron en diagnosticar que la desregulación laboral, el desempleo y la informalidad creciente suponían transformaciones radicales y fuertes golpes para la condición obrera y los sindicatos, la diferencia entre ellas radicaría en la cualificación de los cambios y sus efectos (Santana, 2000: 216). Para la CUT significaban serios riesgos para los trabajadores, 
FS consideraba que surgían espacios que podían ser utilizados para mejorar el trabajo y la vida de aquéllos, y la CGT era la que se mostraba más optimista sobre la oportunidad que ofrecían esos espacios. Si la primera central centraba su análisis y propuestas de acción en la lógica del sistema, criticando la visión de una "adecuación" del trabajador al nuevo modelo laboral y discutiendo las nociones básicas del mismo, calidad y productividad, las otras dos centrales partían de una perspectiva individual señalando que el trabajador debía "potenciarse" y buscar un "lugar" en el nuevo orden.

En ese sentido, mientras la CGT y FS daban como un hecho consumado la instalación del régimen laboral y proponían "adaptarse" al mismo, la CUT intentaría revertir sus fundamentos e imponerle otra trayectoria. Para ello no sólo sostendría la importancia de la negociación, sino también de la organización y movilización, como condiciones del intercambio con las empresas. Aquí es posible notar que las prácticas de intercambio, tanto con el gobierno como con las empresas, tuvieron diferentes objetivos para la CGT argentina oficialista y la CUT, ya que la primera usaría intercambio y negociación para adaptarse al nuevo modelo y conservar lo que pudiera de sus antiguos privilegios corporativos. De todos modos hubo puntos de coincidencia entre las tres centrales del Brasil, ya que defendieron una amplia movilización contra el desempleo, advirtieron que la educación profesional permitiría a los trabajadores no quedar afuera del nuevo mundo laboral, etc.

Más allá de sus diferencias de diagnóstico, CUT, CGT y FS intentaron cierta unidad en la acción, lo que Santana denomina "separación estructural y aproximación coyuntural" (Santana, 2000, 218) Se intentó construir un consenso en torno a cuestiones como la cualificación profesional, la situación de la mujer trabajadora y el desempleo. Asimismo, a fines de 1999, CUT y FS se unieron en una campaña por las 36 horas de trabajo y el contrato nacional para los trabajadores de las montadoras. No obstante, Santana señala las limitaciones de algunas de estas iniciativas: la CUT ha pecado de priorizar en los hechos su inserción en foros institucionales en 
detrimento de la movilización social y sindical, lo que la sumió en cierta parálisis a fines de la década. Por otra parte, cuestiona que redujera su iniciativa a impulsar los proyectos y programas de cualificación, que requirieron de grandes recursos públicos del Fondo de Amparo del Trabajador y no parecía, en el momento de su análisis (2000), demostrar su eficacia ante la exclusión de los trabajadores de los procesos de reestructuración. Por último, advierte que el programa impulsado por la FS para crear centros de oferta de vacantes en las empresas, si bien era relevante en sí mismo, realzaba la inserción defensiva del sindicalismo.

\section{B. LAS NEGOCIACIONES COLECTIVAS.}

Desde su regulación a mediados del siglo XX, la historia de la negociación colectiva en la Argentina puede dividirse en dos etapas, la primera desde 1953, cuando se sancionó la ley regulatoria (14250), hasta fines de la década de 1980, y la segunda hasta la actualidad (Palomino y Trajtemberg, 2006) Entre 1953 y 1988 la negociación colectiva tuvo vigencia plena sólo en períodos breves, afectada por las suspensiones que imponían los reiterados golpes y gobiernos militares. Su forma ha sido descripta como un modelo "paradigmático", caracterizado por su centralización en los grandes sindicatos y en las cámaras empresarias de cada sector de actividad, una fuerte intervención del estado (homologación, personería gremial), identidad política de los sindicatos, extensión universal de la cobertura (sindicalizados, no sindicalizados) y ultra actividad (vigencia hasta la renovación)

.En la etapa 1989 - 1999 encontramos que la negociación colectiva fue beneficiada en este país por una vigencia institucional plena y estable, y que se registraron varios cambios importantes. En primer lugar, la composición de las negociaciones ya no es la misma, los convenios y acuerdos se pactaron a nivel de empresas individuales, y consagraron legalmente cuestiones hasta entonces acordadas informalmente, como la flexibilidad contractual (contratación por tiempo determinado) y la flexibilidad interna de las empresas (cambios en la duración de la jornada, organización del 
trabajo y modalidad de las remuneraciones), en particular durante el segundo gobierno de Menem, cuando se eliminó por decreto la ultra actividad en los convenios y se promovió la negociación por empresa con las comisiones gremiales internas (fines del año 1996) (Battistini: 258)

En segundo lugar, el contexto económico y social también había cambiado, de uno caracterizado por el pleno empleo y la alta afiliación sindical a otro marcado por el aumento inédito de la desocupación y el trabajo informal, facilitando la introducción de la flexibilidad laboral. La negociación colectiva del período, entonces, legitimará esa incorporación, aunque ello significara favorecer la mercantilización de la mano de obra, deteriorando la posición relativamente protegida de los asalariados comprendidos por la misma (Palomino y Trajtemberg, 2006)

También en Brasil los cambios en el régimen laboral pusieron en evidencia la dificultad de afrontarlos con las prácticas sindicales confrontacionistas del pasado (da Silva Costa, 2003, 8) Las renuncias en masa, la difusión en las empresas de programas destinados a anticipar los conflictos, la adhesión ideológica de los trabajadores a los principios de las empresas y el traslado de muchos de ellos al sector servicios, menos proclive a la organización sindical, tuvieron un efecto devastador sobre el nivel de sindicalización y el poder de los sindicatos para proponer iniciativas colectivas y solidarias. La negociación sindical se volvió menos nacional o regional y más dependiente de la realidad y la posibilidad de cada empresa o grupos de empresas, perdiendo el marco más amplio que había tenido en el pasado, cuando los índices salariales fijados por el gobierno promovían una articulación más abarcativa. La lucha para aumentar los salarios por sobre ese índice fue perdiendo relevancia ante la caída del empleo y la necesidad de acordar mecanismos mínimos que garantizaran una estabilidad aunque fuera provisoria.

Es importante señalar que en la Argentina, mientras el sindicalismo oficialista obtenía del gobierno, a través de la negociación o el bloqueo parlamentario, una "reforma posible", es decir una que respetaba la representación de los sindicatos nacionales en las 
negociaciones colectivas, a nivel regional y de empresa ya habían comenzado a registrarse cambios a favor de una mayor flexibilidad en la organización de la producción y del trabajo. Mónica Gordillo advierte que las nuevas empresas automotrices y metalmecánicas instaladas en Córdoba a partir de 1995, como General Motors, FIAT, Toyota y Chrysler, aplicaron pautas flexibilizadoras en los procesos de trabajo, categorías, remuneraciones, duración de la jornada de trabajo y relaciones gremiales al interior de la fábrica, antes que el gobierno nacional promoviera un nuevo salto cualitativo en las reformas a fines de 1996 (Gordillo, 2008)

El análisis de Gordillo sobre la negociación colectiva en las empresas nuevas y en las ya existentes permite apreciar que el sindicato, en este caso el SMATA, siguió una estrategia dual. Por un lado, difería en las primeras la negociación de nuevas formas de organización del trabajo y concentraba la misma en los salarios, aceptando incorporar cláusulas de productividad sólo cuando los avances desreguladores del gobierno lo hicieron inevitable; pero no se apartó de la ultra actividad en otros aspectos y manejó centralizadamente la negociación, recordemos que la seccional Córdoba del sindicato mantuvo una histórica autonomía, para garantizar los acuerdos logrados con las empresas. Por otro lado, aceptaba los cambios de hecho, ya que nunca discutió ni enfrentó los mismos, y ello facilitará su institucionalización a través de los convenios.

Por el contrario, en los sectores sindicales más modernos y más organizados del Brasil la agenda de negociación priorizaría las cuestiones relativas a la gestión y organización del trabajo dentro de las empresas. Según da Silva Costa, la reaparición de componentes de competitividad, como la innovación tecnológica y gerencial, fueron responsables de la introducción de nuevos métodos de organización y gestión de la fuerza de trabajo, con valores ideológicos distintos a los que habían predominado hasta entonces en las relaciones laborales. En el seno de la producción, las políticas de calidad y las inversiones en entrenamiento y cualificación de los trabajadores, así como su involucramiento con los intereses de la empresa, abrieron 
espacios para la experiencia de cambios participativos, lejanos al rigor jerárquico y la división entre concepción y ejecución del taylorismo. Consecuente con ello los sindicatos cambiaron sus posiciones intransigentes del pasado por posturas de negociación y conciliación, que implicaban propuestas de auto - preservación y convergencia de intereses (da Silva Costa: 9)

La autora postula que había surgido una nueva institucionalidad micro - regulatoria, según la cual los contratos colectivos de trabajo y los aparatos normativos internos de las empresas incorporaban nuevos parámetros, nuevas reglas, nuevos espacios y objetivos. Y el nuevo tono de las negociaciones colectivas consistiría desde entonces en la preservación de los empleos, las políticas de formación y cualificación, el desplazamiento de los ajustes salariales fijos a las formas variables de retribución, la conservación de conquistas pasadas, entre otros. Por otra parte, el desafío de los sindicatos era mantener un nivel tradicional de acción colectiva y solidaria cuando estaba amenazada su propia base de representación. En efecto, la polarización de los trabajadores respecto de sus condiciones de empleo y de vida, entre un polo formal y cualificado, y otro informal, descalificado y de bajos salarios, alimentó una ética individualista y competitiva dentro de las empresas, a partir de la cual crecería la presencia de un tipo de trabajador no convencional, no regulado y no reglamentado, que se mantendría lejos del sindicato. En resumen, el desempleo desalentó la movilización y redujo el poder de negociación.

Al final del período que estudiamos, en Brasil se discutía en el Senado Federal la propuesta de que los acuerdos colectivos privados se sobrepusieran legalmente a la legislación incluida en la CLT, con el argumento de que esta impedía la flexibilización del trabajo. Esto apuntaba, según Castro, a ampliar aún más la posibilidad de un uso "predatorio" de la fuerza de trabajo, con sindicatos debilitados por la amenaza del desempleo (da Silva Costa: 10). Teniendo en cuenta que la CLT garantizaba una base mínima de derechos laborales, privilegiar la negociación sobre la legislación implicaría la reducción y manipulación de esa base. Lo cual no solo supondría una 
flexibilización laboral sino también una "desreglamentación" laboral. Esta situación es más acuciante para los sindicatos sin una tradición fuerte de confrontación y radicados en regiones con empresas que no invierten en valorizar sus recursos humanos. Exceptuando los casos de los metalúrgicos de San Pablo o del ABC paulista, y de los trabajadores de la industria petroquímica, para los sectores con alto desempleo y débil representación sindical la legislación de la CLT y la regulación estatal constituían los únicos instrumentos para poner límites mínimos a los criterios de contratación y uso del trabajo. En estos casos la posición conciliadora y no confrontacionista era lo habitual, la negociación se subordinaba a las concesiones que quisieran hacer las empresa y a veces sin que el sindicato tuviera acceso a ellas.

No obstante ello, el sindicalismo con mayor tradición combativa, como el metalúrgico del $\mathrm{ABC}$ paulista, también sufriría cambios debido a la reestructuración productiva, adoptando un nuevo estilo de acción inclinado menos a la confrontación directa que a la conciliación y cooperación con las empresas, el así denominado "sindicalismo ciudadano" (Praun, 2012: 110) Al final de la década de 1980 ya aparecía, en el discurso de los dirigentes metalúrgicos de San Bernardo del Campo, la noción de que la huelga, la lucha anticapitalista y anti patronal habían sido propia de la resistencia a la dictadura militar, y que debían ser abandonadas por una orientación de tono propositivo, tendiente a democratizar las relaciones entre capital y trabajo. Esta se consolidó como respuesta a las políticas económicas y laborales de Collor, y a su continuidad más allá de la caída de su gobierno, e irradió hacia otros dirigentes y organizaciones dentro de la CUT. Se trataba de una adaptación táctica a una coyuntura adversa, en la cual se subordinaba la acción de clase a un proyecto más general de llegada al poder a través de las instituciones democráticas (ergo la candidatura presidencial de Lula).

A partir de su incorporación a las Cámaras del Sector Automotriz, en 1992 - 1993, el sindicato postuló que este debería ser un espacio de cogestión de las políticas industriales y reclamó participar en una "reestructuración negociada", que reemplazara los cambios 
productivos unilaterales ya en curso. Dicha negociación pasaba por colaborar en la reestructuración garantizando la contrapartida de la conservación de los puestos de trabajo y una mejor distribución de las ganancias obtenidas por los incrementos de productividad. El sindicato participaría desde entonces en los esfuerzos compartidos para dotar de capacidad competitiva y productividad a las empresas, incluso compitiendo contra las diferentes plantas de la misma firma, incluso las radicadas en países vecinos como la Argentina, para obtener los mejores contratos. Esto implicaba abandonar la herencia clasista y contestataria y actuar, desde entonces, "en sociedad" con la patronal para alcanzar metas comunes y competir con otras plantas. En algunos casos, como en la Volkswagen de São Bernardo do Campo, la puesta en práctica del "banco de horas" de común acuerdo con el sindicato en 1996 se anticipó en dos años a la legislación federal al respecto (Praun: 124) La colaboración sindical contribuyó a la imposición en las empresas del $\mathrm{ABC}$ de los mecanismos típicos del modelo de "fábrica delgada", como la tercerización de actividades en las líneas de producción, y a su consecuencia de precarización del trabajo.

La colaboración entre los expertos y el movimiento sindical frente a los desafíos locales de la globalización.

Algunos autores han señalado que los sindicatos, debido a la carencia de proyectos definidos, no tuvieron una incidencia significativa en las políticas estatales de la Argentina de los años 90’, lo que obligó a reformular las estrategias propias para sumarse a las del gobierno (Palomino: 403) Si bien el sindicalismo oficialista consiguió de este, mediante su control de ciertos espacios institucionales, una "reforma posible" es decir una que respetaba la representación de los sindicatos nacionales en las negociaciones colectivas, pronto debió enfrentar el hecho de que no estaba preparado para hacerse cargo de los cambios a favor de una mayor flexibilidad en la organización de la producción y del trabajo. La nueva institucionalidad micro - regulatoria, en otras palabras los nuevos parámetros, las nuevas reglas, los nuevos espacios y objetivos que habían incorporado las empresas automotrices y metalmecánicas a la producción ya en 
los años ochenta, pronto se presentaría como un desafío para los dirigentes en las negociaciones colectivas.

En la UOM, por caso, el desafío pasaba por la distancia entre las normas consagradas por el Convenio Colectivo de Trabajo 260/75, negociado en los primeros ańos setenta, y las nuevas normas que las seccionales y las comisiones internas negociaban con las empresas (Battistini: 412; Bisio y Freytes Frey, 1997: 170) El secretariado nacional del sindicato no estaba dispuesto a renunciar al convenio nacional, ante la evidencia de que las cámaras patronales privilegiaban la negociación por empresa, pero advertía su falta de actualización en los nuevos temas que implicaba la flexibilización laboral. En ese contexto los dirigentes nacionales debieron confiar en la experticia de los técnicos durante las negociaciones. En un primer momento los expertos habían comenzado a prepararse a nivel de las seccionales, según un estudio de Bisio y Freytes Frey, cuando la falta de articulación entre estas y la conducción central del sindicato llevó a una descentralización de hecho (Bisio y Freytes Frey: 173) El testimonio de un técnico, citado por Battistini, es ilustrativo del proceso de innovación en el que estuvieron involucrados:

"No teníamos idea; o sea, era cierto, teníamos un país cerrado. Yo pienso que nosotros como organización gremial estábamos enfrascados en un modelo, cuando nos vino todo esto nos desbordó. Tardamos mucho pero nos dimos cuenta, estudiamos mucho, se formaron equipos acá adentro y hoy en día hasta los dirigentes no lo entienden; entonces, empiezan a confiar en nosotros en las negociaciones, cosa que antes hacían ellos en forma personal y ya no lo hacen más y nos ponen a nosotros a negociar." (Battistini: 413)

$\mathrm{Si}$ bien la negociación ponía en evidencia las tensiones que cruzaban a la UOM, entre lo formal (defensa del CCT 260/75) y lo real (los acuerdos por empresa) y entre el Secretariado Nacional y las seccionales y comisiones internas, las nuevas características que aquella asumía legitimaron la formación de equipos técnicos en la administración central de la UOM que actuarían en virtud de una doble autoridad: su experticia y su ubicación en el nivel político más alto de la organización (Battistini: 416) 
Una de las novedades más significativas introducidas por la CTA fue la creación de centros de estudios, investigación y formación sindical, cuyos planteles de docentes, asesores y consultores estarían formados por intelectuales, investigadores sociales y profesionales. Como dice Palomino "estos sindicatos concibieron el aporte de ideas como un recurso estratégico para su actividad, y estimularon incluso algunas búsquedas afines en el resto del sindicalismo. Esta reorientación es novedosa para un ambiente como el sindical, en el que predominó una tradición anti intelectual desde mediados de siglo" (Palomino: 411)

La CGT oficialista, por su lado, también incorporó intelectuales a un centro de estudios propio; sin embargo no tuvieron un rol práctico en las organizaciones afiliadas, limitándose a la vinculación con otras organizaciones, sindicales y no sindicales. En muchos casos esos intelectuales eran "asesores jurídicos" y económicos, reclutados dentro de los planteles del establishment empresarial (Palomino, ídem)

En el caso de Brasil, los sindicatos integrados en la CUT advirtieron que los desafíos de la globalización debían enfrentarse no solo al nivel de las empresas radicadas en el país, como señalamos para San Bernardo del Campo (SP) ABC, sino también en el campo internacional. La señal de alarma se hizo sentir cuando la Organización Mundial del Comercio llevó a la Organización Internacional del Trabajo, en los primeros ańos noventa, la propuesta de agregar cláusulas sociales a los acuerdos comerciales. A instancias de la Escuela Sur de la CUT, en 1994, comenzó a discutirse, la creación de un observatorio que generara conocimiento sobre las nuevas formas de organización del trabajo y las estrategias para enfrentarlas. Tres años después surgía el Instituto Observatorio Social, "una organización sin fines de lucro que tiene como objetivo la generación de conocimiento para el mundo sindical y el mundo del trabajo. Con alcance nacional e internacional, el IOS realiza investigaciones y estudios especializados, con metodologías y procesos participativos, que contribuyen a la acción sindical, el diálogo social y el desarrollo sustentable." (Instituto Observatorio 
Social, disponible en http://www.observatoriosocial.org.br)

El IOS tuvo dos fuentes que son relevantes para nuestro estudio: por un lado se nutrió de dos centros, como el Departamento Intersindical de Estadística y Estudios Socioeconómicos (DIEESE) y el Centro de Estudios de Cultura Contemporánea (CEDEC), que ya tenían arraigo en el campo sindical desde la década de 1950, y por otro lado, el CEDEC tenía vínculos estrechos con el campo sindical internacional, ya que había sido apoyado financieramente por las centrales FNV holandesa y la DGB alemana.

Nuestra hipótesis de trabajo es que algunos sectores del sindicalismo, aunque fuera tardíamente o debiendo superar viejos prejuicios hacia la inclusión de actores no obreros, comenzaron a organizar centros de estudio, investigación y formación con un sentido estratégico. El acceso a la información sobre nuevas tecnologías, procesos productivos y otros datos esenciales, en un contexto de graves incertidumbres y pérdida de iniciativas políticas, apareció como un recurso valioso porque permitiría a los trabajadores entender su nueva situación en relación con otros trabajadores, incluso de otros países (y de empresas de la misma firma radicadas en el exterior) y su potencial para la acción colectiva. La búsqueda de esos nuevos conocimientos no se restringió al campo local sino que incursionaría en espacios internacionales y con aliados transnacionales, como foros, sindicatos y organismos laborales mundiales como la OIT.

En este sentido el comportamiento de los expertos que colaboraron con los sindicatos y los trabajadores puede ser analizado a partir del concepto "cosmopolitismo arraigado", propuesto por Sydney Tarrow para caracterizar a un movimiento integrado por activistas con recursos locales y oportunidades políticas que pueden utilizar en la creación de coaliciones transnacionales, mientras que sus experiencias transnacionales puede ser la fuente de innovaciones en el repertorio local del conflicto ante fenómenos nuevos como la globalización. En una reciente ponencia, Mónica Gordillo señala que "las experiencias de transnacionalización sindical [de fines de la década de 1970 y comienzos de la siguiente] permitieron externalizar 
reclamos e internalizar marcos de acción y opciones superadoras para repensar el papel del sindicalismo en el nuevo contexto, algunas de ellas propiciadoras de la democratización sindical." (Gordillo, 2016) Y sigue diciendo: "La primera cuestión a aclarar es que no se trata de un fenómeno nuevo sino que a lo largo de la historia pueden encontrarse muchísimos ejemplos de su actuación. Lo que es necesario ponderar entonces es cuándo cumple un papel relevante como para convertirlo en objeto de estudio, y cómo impacta su actuación en los escenarios domésticos. Es decir, ¿para qué sirve estudiarlo? Considero que en determinados momentos como el de la crisis de la relación salarial fordista y la consecuente instalación de dictaduras, su papel fue fundamental para legitimar una salida democrática y para adquirir nuevos conocimientos que le permitieran enfrentar los cambios que se avecinaban, impactando a su vez en los escenarios nacionales."

Para el activismo transnacional es fundamental que la militancia trascienda el escenario nacional y se convierta en lo que Tarrow denomina "cosmopolitismo arraigado": "personas o grupos que llevan sus quejas formadas domésticamente a la sociedad internacional cuando esos reclamos no pueden ser por más tiempo dirigidos internamente, movilizando fuentes y oportunidades domésticas e internacionales para avanzar reclamos de parte de actores externos, contra oponentes externos o en favor de objetivos que sostienen en común con aliados transnacionales" (Tarrow citado por Gordillo, 2016)

Los expertos en las relaciones entre capitaly trabajo frecuentemente han integrado redes internacionales como parte de su formación profesional, sin embargo no es común que lo hicieran para adquirir nuevos conocimientos en función de enfrentar el impacto local de transformaciones en el orden político, social y productivo mundial. A continuación reseñamos una experiencia argentina que, más allá de las diferencias históricas, nos puede resultar útil para comprender este fenómeno. 
LOS EXPERTOS EN EL INICIO DE LA REGULACIÓN ESTATAL DE LAS relaciones capital - trabajo. Alejandro Unsaín y la OIT. La interacción entre los expertos que crearon los primeros organismos públicos de regulación del trabajo en la Argentina de comienzos del siglo XX, el movimiento sindical y la Organización Internacional del Trabajo es un caso ilustrativo de cómo unos actores nacionales se integraban en el campo global de relaciones y conocimientos en busca de actualizar los propios y utilizaban lo adquirido para innovar sus "repertorios locales" en el contexto de los nuevos conflictos y desafíos. Las nuevas ideologías adoptadas por el movimiento sindical, recordemos que a lo largo de la década de 1920 surgieron los partidos comunistas en diferentes países de América Latina, y el reconocimiento de los trabajadores como nuevo sujeto de derecho, la Constitución mexicana de 1917 sentaba un precedente, crearían un campo de intervención para burocracias especializadas, provistas de un espíritu racionalista y cientificista. (Herrera González, 2016)

Los organismos técnicos del Estado, administrados por profesionales y técnicos, que se ocuparían de las cuestiones laborales aparecieron en la región entre 1907 y 1926. En el caso de Argentina el Departamento Nacional del Trabajo (DNT) fue creado en 1907. Es interesante reseñar que, como ha señalado Juan Suriano, en la trayectoria que llevó a su aparición están muy presentes los intercambios con experiencias intelectuales y prácticas extranjeras, lo que el autor llama "el taller internacional" en el que aprenderían los nuevos "expertos" locales (Suriano, 2013) Para 1907 no existía en este país un bagaje de información suficiente sobre la cuestión laboral, que permitiera elaborar legislación ni mucho menos los diagnósticos que necesitaba un organismo oficial. En resumen "la información existente era poco precisa, fragmentaria, incompleta y carecía de sistematicidad".

Las experiencias relativas a políticas sociales que se llevaban a cabo en los viejos países industrializados de Europa y Estados Unidos o en las nuevas economías emergentes como Canadá y Nueva Zelanda aparecían como fuentes alternativas de información y conocimiento para los profesionales, técnicos e intelectuales convocados a participar 
en proyectos como el Código de Trabajo impulsado por Joaquín V. González (1904) o la creación del DNT. Entre los primeros había doctores en medicina y en jurisprudencia, como Armando Claros, el doctor Carlos Malbrán del Departamento Nacional de Higiene, Juan Bialet Massé, así como los socialistas Augusto Bunge, Leopoldo Lugones, Manuel Ugarte, José Ingenieros, Enrique del Valle Iberlucea y Pablo Storni. Estos siguieron varias estrategias para apropiarse del saber en el "taller internacional": el contacto con instituciones académicas extranjeras, visitas exploratorias a los organismos laborales oficiales y lecturas de la bibliografía especializada.

Aunque la sanción del proyecto del Código de Trabajo se frustraría en su momento, debido al desinterés de los parlamentarios y la oposición del sindicalismo anarquista y los empresarios industriales, su contenido sería fuente de información de futuras leyes laborales, inspiraría la creación del DNT y un nuevo proyecto de código, esta vez encargado por el presidente Yrigoyen al Dr. Alejandro Unsaín, funcionario del DNT, en 1921. Unsaín, de quien nos ocuparemos más adelante, formaba parte de un grupo de profesionales que se habían integrado a un circuito internacional muy fluido de ideas e información sobre políticas laborales. Según Suriano,

"A partir del canje de publicaciones con las instituciones extranjeras, la llegada al país de expertos extranjeros, los viajes de sus funcionarios a congresos internacionales o la visita a instituciones laborales del exterior se establecieron redes transnacionales que enriquecieron de manera sustancial la formación de los funcionarios locales. La adopción de conceptos y métodos de especialistas extranjeros, sumados a las observaciones y experiencias en el campo local, contribuyeron a conformar un dinámico campo de funcionarios especializados en conocimientos de cuestiones laborales. La activa participación argentina en estas redes aumentó los contactos internacionales y permitió un fructífero intercambio entre los expertos en el tema y las principales instituciones laborales del mundo." (Suriano, 126)

Uno de los espacios privilegiados de esas transferencias sería la Oficina Internacional del Trabajo (OIT), creada en el año 1919 por 
la Sociedad de las Naciones, con el propósito de mejorar las relaciones laborales según los principios fundacionales de la justicia social, la cooperación internacional y la paz mundial. La Argentina fue invitada tempranamente a integrarse a este organismo, en oportunidad de realizarse la Conferencia Internacional del Trabajo en Washington. El presidente Yrigoyen envió una delegación compuesta por un representante obrero y uno patronal, y dos delegados oficiales, uno de los cuales era el Dr. Unsaín. La significación de este hecho es destacada por Suriano: "En realidad se estaba plasmando la concreción de un viejo anhelo de muchas organizaciones obreras $\mathrm{y}$ de algunas instituciones estatales de conformar normas comunes transnacionales de protección a los trabajadores, esto es, el derecho internacional obrero que se plasmaría en la OIT." (Suriano, 127)

En buena medida el prestigio de la nueva agencia provendría de su propia organización: su Consejo de Administración estaba constituida por una estructura tripartita, conformada por representantes patronales, obreros y gubernamentales. En las deliberaciones había intercambio de información y experiencias y los acuerdos tenían la legitimidad de haber resultado del consenso entre obreros y patrones (Caruso, 2014: 28) Si bien Argentina permanecería como miembro de la OIT y esta abriría una corresponsalía en el país, la relación no fue siempre fluida: los convenios sobre duración de la jornada laboral y otras cuestiones elaborados en Washington en 1919 serían ratificados recién doce ańos después.

El Dr. Alejandro Unsaín fue un passeur entre el campo estatal específico y local de la regulación del trabajo y un campo mucho mayor, global, donde confluían los debates provenientes de otros espacios nacionales, como era la OIT. Como dijimos antes los expertos argentinos no eran ajenos a ese campo global de conocimientos, ya que antes de la creación de la OIT habían completado su formación en derecho laboral con lecturas e intercambios personales provenientes de otros países, pero ahora su participación era más activa y compleja porque aportaban su experticia para constituir y enriquecer no solo el campo local, como había sido la creación del DNT, sino también el global y el regional. 
Como señala Laura Caruso reseñar su trayectoria es, más que un esbozo de historia de vida, el de la "construcción de un campo estatal específico de regulación de las relaciones de trabajo y, en particular, de la consolidación del DNT y su vínculo con la OIT" (Caruso, 20) Unsaín era director interino del DNT cuando Yrigoyen lo designó delegado oficial a la Conferencia de la OIT de 1919 en Washington, allí fue incorporado al Consejo de Administración de la misma representando a la Argentina y se estableció en Ginebra, sede permanente de la agencia. Años después volverá al país como corresponsal de la OIT. Su presencia en el Consejo de Administración mantuvo vigente el contacto de la agencia con el mundo del trabajo argentino pero, además, como director y redactor principal del Boletín del DNT difundiría las deliberaciones y acuerdos logrados en las conferencias internacionales y regionales de la misma.

Por último puede decirse que Unsaín, passeur al fin, tuvo la visión, aunque nunca llegará a realizarla, de establecer un nexo entre el DNT y los organismos similares o equivalentes de América Latina, un puente que se hará efectivo recién con las conferencias americanas sobre el trabajo, a partir de 1936. Unos veinte años antes, Unsaín y otros expertos en derecho laboral presentaron, en el Congreso Americano de Ciencias Sociales realizado en Tucumán, el proyecto de crear una oficina de intercambio de información con países vecinos sobre hechos, estadísticas y legislación obrera, de atender consultas y proveer información propia. Unsaín advertía sobre la falta de intercambios entre países de la región, señalando la paradoja de que en las publicaciones especializadas de Argentina "comentamos [...] las leyes europeas, y encontramos serias dificultades para conseguir el texto de la ley de accidentes de trabajo sancionada en el Perú” (citado por Caruso: 18)

\section{Conclusiones}

La referencia a los expertos que en las primeras décadas del siglo $\mathrm{XX}$ actuaron como conexiones entre las agencias internacionales del trabajo, los organismos nacionales de regulación laboral y el movimiento obrero, puede ayudarnos a complejizar nuestra 
perspectiva sobre los actores que en los años noventa colaboraron con los trabajadores y los sindicatos para enfrentar el impacto local de la globalización.

La aparición inesperada de una nueva institucionalidad micro - regulatoria en el mundo de la producción y el trabajo, en la cual los acuerdos logrados en el nivel de las empresas estaban alejados considerablemente de las normas negociadas por los sindicatos nacionales, ya que incorporaban nuevos parámetros, nuevas reglas, nuevos espacios y objetivos de producción, impulsó a los técnicos al primer plano de las negociaciones colectivas entre sindicatos y empresas. Con el consentimiento de los dirigentes nacionales, no siempre libre de desconfianzas, los expertos pasaron de ejercer su asesoramiento del nivel seccional al central. Su experticia en las relaciones laborales, en las dimensiones legales, tecnológicas y organizativas de la producción, los hacía imprescindibles pero no siempre estaban preparados para comprender y enfrentar el desafío que representaba la reestructuración productiva.

El origen global de estos cambios, es decir la necesidad imperativa de países como la Argentina y el Brasil de ser competitivos en un mercado internacional que imponía sus propias reglas, orientó a los expertos a establecer nexos con un campo de conocimientos y experiencias también global, donde podrían interactuar con otros expertos. Aquí hay cierta semejanza en los comportamientos de los expertos de las primeras y de las últimas décadas del siglo. La necesidad de darle más consistencia al cuerpo de información fáctica y teórica existente, que se requería para el proyecto de Código del Trabajo de Joaquín V. González o del DNT, había impulsado a los médicos, docentes y profesionales del derecho que aquél había convocado a recurrir al "taller internacional", a través del contacto con instituciones académicas extranjeras, visitas exploratorias a los organismos laborales oficiales y lecturas de la bibliografía especializada. Por su parte, los técnicos, abogados y sociólogos de fines de siglo acudieron a distintos foros del campo sindical internacional, específicamente a las centrales FNV holandesa y la DGB alemana en el caso de Brasil, y a la propia CUT en el de los 
expertos argentinos, en la búsqueda de información y asesoramiento técnico y sindical.

Por otro lado los expertos contaban con un capital propio en ideas y experiencias, que habían adquirido durante su formación profesional, que ponían en juego al establecer nexos con el campo global y que les serviría para innovar sus "repertorios locales". En las primeras décadas del siglo XX, Alejandro Unsaín fue un nexo importante entre la regulación estatal del trabajo en la Argentina y un campo global donde confluían los debates provenientes de otros espacios nacionales, como era la OIT. Unsaín y otros expertos argentinos no eran ajenos a ese campo global de conocimientos, ya que habían completado su formación profesional con lecturas e intercambios personales provenientes de otros países, pero su participación llegaría a ser más activa y compleja porque aportaban su experticia para constituir y enriquecer no solo el campo local, como había sido la creación del DNT, sino también el global y el regional.

No es simple coincidencia que una parte del sindicalismo brasilero, como los metalúrgicos del $\mathrm{ABC}$ y la CUT, constituyeran un centro de estudios y formación sindical con vínculos con algunas centrales europeas, como las FNV holandesa y la DGB alemana, al mismo tiempo que se adaptaban a la coyuntura adversa del triunfo electoral de Collor de Mello, la reestructuración productiva y las limitaciones legales al derecho de huelga en el sector público, reorientándose al "sindicalismo ciudadano". La información sobre los cambios tecnológicos y organizativos sucedidos en las plantas europeas de las empresas radicadas en Brasil y sobre la forma como los habían afrontado los sindicatos "hermanos" del viejo continente, permitiría dar contenido a su nueva estrategia de actuar como un socio crítico de la patronal, reclamando una "reestructuración negociada" de los procesos productivos que reemplazara los cambios productivos unilaterales ya en curso. El otrora sindicalismo combativo abandonaría su herencia clasista y anticapitalista y participaría desde entonces, junto a los empresarios, en el esfuerzo de volver competitivas a las empresas radicadas en el país, a cambio 
de garantizar la conservación de los puestos de trabajo y una mejor distribución de las ganancias obtenidas por los incrementos de productividad.

\section{BibLIOGRAFÍA}

BISIO, RAÚL Y FREYTES FREY, ADA (1997) "Nuevos escenarios de negociación laboral. UOM vs. SMATA: ¿divergentes planteos estratégicos de acción sindical?” en Villanueva, Ernesto. Empleo y globalización. La nueva cuestión social en la Argentina. Quilmes, Universidad Nacional de Quilmes.

CARUSO, LAURA (2014) "La política laboral argentina en la inmediata posguerra: una perspectiva internacional, 19071925.” Relaciones. Estudios de historia y sociedad, México, El Colegio de Michoacán, vol. XXXV, núm. 138, [Disponible en: http://www.redalyc.org/articulo.oa]

COELHO PRADO, MARIA LIGIA (2011) "América Latina: historia comparada, historias conectadas, historia transnacional", Anuario de la Escuela de Historia, Rosario, Facultad de Humanidades y Arte, UNR, No 24 [Disponible en: http://www. rephip.unr.edu.ar> Facultad de Humanidades y Artes $>$ FHUMyAR - Revistas]

BATTISTINI, OSVALDO (2000). La negociación colectiva y la estructura sindical en la Argentina (1988 - 1989), tesis de posgrado presentada en la maestría Ciencias Sociales del Trabajo, Centro de Estudios Avanzados, Universidad Nacional de Buenos Aires.

DA SILVA COSTA, MÁRCIA (2003) "Reestructuración productiva, sindicatos y flexibilización de las relaciones de trabajo en Brasil", en RAE-eletrônica, v. 2, n. 2 [Disponible en: http://www.scielo.br/pdf/raeel/v2n2/v2n2a10]

DEVOTO, FERNANDO Y FAUSTO, BORIS (2008) Argentina - Brasil, 1850 - 2000. Buenos Aires, Sudamericana.

DROLAS, M. ANA (2004) "Futuro y devenir de la representación sindical: las posibilidades de la identificación", en Battistini, 
Osvaldo (comp.) El trabajo frente al espejo. Continuidades y rupturas en los procesos de construcción identitaria de los trabajadores. Buenos Aires, Prometeo.

ETCHEMENDY, S. Y PALERMO, V. (1998) "Conflicto y concertación. Gobierno, Congreso y organizaciones de interés en la reforma laboral del primer gobierno de Menem (19891995)",

GORDILLO, MÓNICA (2008) "Institucionalización de cambios organizacionales en los sectores de punta: la industria metalmecánica de Córdoba en los '90", en Anuario IEHS Nº 23. (2016) "De militantes sindicales a activistas transnacionales: algunas experiencias en el Cono Sur", ponencia presentada en el V Congreso Latinoamericano de Historia Económica, San Pablo, Brasil.

HERRERA GONZALEZ, PATRICIO (2016) "Las Conferencias Americanas del Trabajo y el debate sobre las condiciones laborales del proletariado de América Latina, 1936-1946", ponencia presentada en el IV Workshop Trabajadores, empresarios y comunidades obreras: conceptos, problemas y escalas de análisis, Rosario, Universidad Nacional de Rosario.

LEVITSK, STEVEN (2004) "Del sindicalismo al clientelismo. La transformación de los vínculos partido - sindicatos en el Peronismo, 1983 - 1999", Desarrollo Económico, Buenos Aires, IDEA, vol. 44, nº 173.

MARTINS RODRIGUES, LEÔNCIO (1992) "O sindicalismo brasileiro: a crise do corporativismo", em AAVV. Nuevas tendencias en el sindicalismo: Argentina - Brasil. Buenos Aires, Biblos - Fundación Simón Rodríguez.

NEIBURG, FEDERICO Y PLOTKIN, MARIANO (2004) "Intelectuales y expertos. Hacia una sociología histórica de la producción del conocimiento sobre la sociedad en la Argentina”, en Neiburg, F. y Plotkin, M. (comp.) Intelectuales y expertos. La constitución del conocimiento social en la Argentina. Buenos Aires, Paidós.

PALOMINO, HÉCTOR (2005) "Los cambios en el mundo del 
trabajo y los dilemas sindicales", Suriano, Juan (dir.) Nueva Historia Argentina. Dictadura y democracia (1976-2001), Buenos Aires, Sudamericana.

PRAUN, LUCI (2012) "Sindicalismo metalúrgico no ABC paulista: da contestação à parceria”, em de Souza, Cangussu y Vieira Trópia (org.) Sindicatos Metalúrgicos no Brasil Contemporâneo. Belo Horizonte, Fino Traço.

SANTANA, MARCO AURÉLIO. "O sindicalismo brasileiro nos anos 1980-2000: do ressurgimento à reorientação" em Estudos do Trabalho, ano $\mathrm{V} \mathrm{n}^{\circ} 8$, Rede de Estudos do Trabalho [Disponible em: www.estudosdotrabalho.org] (2000) "As centrais sindicais brasileiras e a reestruturação produtiva: análises e propostas", em Sociologias, Porto Alegre, ano $2 \mathrm{n}^{\circ}$ 4 [Disponible em: http://www.scielo.br/cgi-bin/wxis.exe/iah/] TARROW, SYDNEY (2010) El nuevo activismo transnacional. Barcelona, Editorial Hacer.

Fecha de Recepción del Artículo: 20 de julio de 2016 Fecha de Aceptación: 30 de septiembre de 2016 